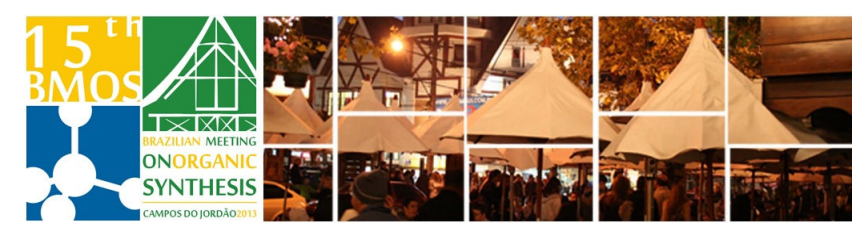

\title{
Brønsted Acid-Catalyzed Highly Diastereoselective Michael- type Addition of Azlactones to Enones
}

\author{
Eloah P. Ávila, Amanda C. de Mello, Renata Diniz and Giovanni W. Amarante* \\ *giovanni.amarante@ufjf.edu.br
}

Keywords: Michael Addition, Brønsted acid, Organocatalysis

\section{INTRODUCTION}

The Michael addition reaction is a powerful synthetic tool to the formation of a new $\sigma$ C-C bond used in the synthesis of complex organic molecules. Recently, several research groups have focused in the development of this reaction in a selective

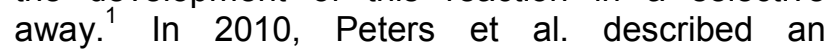
asymmetric Michael addition between chalcones and azlactones by using Palladium as a catalyst. ${ }^{2}$ Thus, in this communication we show our results on a Brønsted acid catalyzed stereoselective Michaeltype addition of azlactones to enones.

\section{RESULTS AND DISCUSSION}

Our studies began with the preparation of the azlactone (1a) and enone (2a) skeletons, which is easily available by using literature protocols. After, we start the optimization of the reaction conditions which is summarized in the table 1.

Table 1. Optimization of reaction conditions for the diastereoselective Michael-type reaction ${ }^{[a]}$.

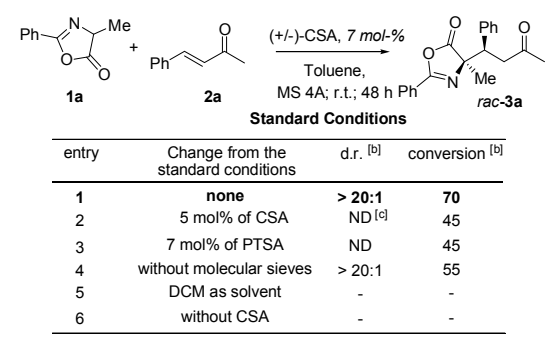

[a] Reactions were carried out using $0.2 \mathrm{mmol}$ of $1 \mathrm{a}, 0.014$ mmol of catalyst $(7.0 \mathrm{~mol} \%)$, and $0.21 \mathrm{mmol}$ of $2 \mathrm{a}(0.2 \mathrm{M}$ in azlactone). [b] Determined by ${ }^{1} \mathrm{H}$ NMR analysis of crude reaction mixture. [c] Not determined.

To our satisfaction using $7 \mathrm{~mol} \%$ acid canforsulfonic catalyzes the reaction, providing the Michael adduct $3 a$ in high conversions and excellent diastereoselectivities, > 20:1 dr. Since the reaction conditions in hand, we evaluated the scope of the method (Table 2).

Various azlactones and enones were well tolerated. For example, the reaction in the presence of a steric bulk azlactone works quite well, providing the adduct 3c in moderate yield and with high diastereoselectivity. Dibenzylidene acetone (dba) as Michael acceptor gave the corresponding 1,4- addition products in good yields and perfect control of the regio- and stereochemistry. To the best of our knowledge, this consists the first highly diastereoselective desymmetrization of $\mathrm{dba}$ catalyzed by a Brønsted acid.

Table 2. Diastereoselective Michael-type addition of azlactones to enones ${ }^{[a]}$.

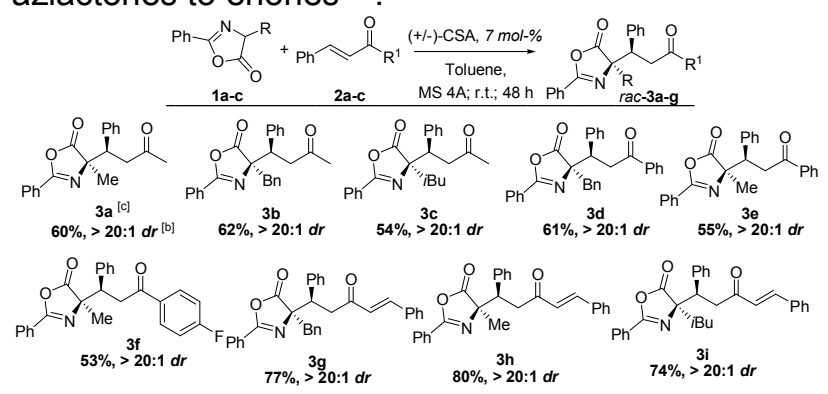

*[a] Reactions were carried out using $0.2 \mathrm{mmol}$ of 1a-c, 0.014 $\mathrm{mmol}$ of $(+/-)-\mathrm{CSA}(7.0 \mathrm{~mol} \%)$, and $0.21 \mathrm{mmol}$ of $2 \mathrm{a}-\mathrm{c}$ in $\mathrm{PhMe}$ (0.2 $\mathrm{M}$ in azlactone). [b] Determined by ${ }^{1} \mathrm{H}$ NMR analysis of the crude reaction mixture. [c] Relative stereochemistry of $\mathbf{3 a}$ was determined by X-ray crystallography and the other products were assigned on the analogy.

\section{CONCLUSION}

In summary, a Brønsted acid catalyzed regio- and diastereoselective Michael addition of azlactones to enones is presented. Protected 1,2-anti amino acid derivatives were synthesized in moderate to good yields and with complete control of the relative stereochemistry. Besides, a new $\sigma \mathrm{C}-\mathrm{C}$ bond and two stereogenic centers are created, one of them a quaternary center. Moreover, for the first time, the diastereoselective desymmetrization of $\mathrm{dba}$ catalyzed by a Brønsted acid is reported. ${ }^{3}$ The development of an enantioselective version as well as mechanisthical investigations are ongoing and will be reported in due course.

\section{ACKNOWLEDGEMENTS}

FAPEMIG, CAPES, UFJF, CNPq and Rede Mineira de Química for financial support.

\section{REFERENCES}

${ }_{1}^{1}$ Ávila, E. P.; Amarante, G. W. ChemCatChem 2012, 4, 1713.

${ }^{2}$ Weber, M.; Jautze, S; Frey, W.; Peters, R. J. Am. Chem. Soc. 2010, 132, 12222.

${ }^{3}$ Ávila, E. P.; De Mello, A. C.; Diniz, R.; Amarante, G. W. Eur. J. Org. Chem. 2013, 10, 1881. 